\title{
A two-dimensional analytical solution for groundwater flow in a leaky confined aquifer system near open tidal water
}

\author{
Zhonghua Tang ${ }^{1}$ and Jiu J. Jiao ${ }^{2}$,* \\ ${ }^{1}$ Faculty of Engineering, China University of Geosciences, Wuhan, 430074, P. R. China \\ ${ }^{2}$ Department of Earth Sciences, University of Hong Kong, Room 302, James Lee Building, Pokfulam Road, Hong Kong, PR China
}

\begin{abstract}
:
Groundwater in coastal areas is commonly disturbed by tidal fluctuations. A two-dimensional analytical solution is derived to describe the groundwater fluctuation in a leaky confined aquifer system near open tidal water under the assumption that the groundwater head in the confined aquifer fluctuates in response to sea tide whereas that of the overlying unconfined aquifer remains constant. The analytical solution presented here is an extension of the solution by Sun for two-dimensional groundwater flow in a confined aquifer and the solution by Jiao and Tang for onedimensional groundwater flow in a leaky confined aquifer. The analytical solution is compared with a two-dimensional finite difference solution. On the basis of the analytical solution, the groundwater head distribution in a leaky confined aquifer in response to tidal boundaries is examined and the influence of leakage on groundwater fluctuation is discussed. Copyright (c) 2001 John Wiley \& Sons, Ltd.
\end{abstract}

KEY WORDS coastal aquifer, groundwater head fluctuation, open tidal water

\section{INTRODUCTION}

Coastal groundwater regimes have a significant impact on the environmental and ecological conditions in coastal areas. The groundwater head fluctuation caused by the tidal effect influences the stability of slopes and engineering structures along the coast. For many environmental and engineering problems it is important to understand the response of groundwater to tidal fluctuation of coastal water (Pontin, 1986; Liu, 1996). Jacob (1950) derived a one-dimensional equation to describe the change of groundwater head in a confined aquifer in response to sinusoidal oscillations in sea level. This equation has been widely used to analyse the transmission of a tidal fluctuation in a confined aquifer (Ferris, 1951; Erskine, 1991; Fetter, 1994). There are cases where the assumption of one-dimensional flow is not realistic. As a result of complicated hydrodynamic mechanisms and irregular coastline, tides at various locations along the coastline may display a gradual change in tidal range and in the time of occurrence of high and low waters. This is quite obvious in areas where the coastline is highly irregular such as harbour or estuary areas (e.g. Money, 1986; Hong Kong Observatory, 1999). Sun (1997) extended the traditional one-dimensional solution into two-dimensional groundwater flow to investigate the groundwater response in a confined aquifer to tides with amplitude and phase that change along the coastal boundary.

A key assumption behind the cited equations is that the groundwater flow in the aquifer is confined. In a coastal aquifer system, there is usually an unconfined aquifer above one or more confined aquifers (White and Roberts, 1994; Chen and Jiao, 1999). The pressure waves in unconfined aquifers tend to be damped because the storage coefficient is usually several orders of magnitude larger than the confined * Correspondence to: Dr J. J. Jiao, Department of Earth Sciences, University of Hong Kong, Room 302, James Lee Building, Pokfulam
Road, Hong Kong, PR China. E-mail: jjiao@hkucc.hku.hk 
storage coefficient that governs pressure changes at depth (Erskine, 1991, Millham and Howes, 1995; Chen and Jiao, 1999). White and Roberts (1994) concluded that the attenuation of the tidal response with distance varies markedly for confined and unconfined aquifers and that very often significant fluctuations are unlikely to extend to more than about 20 to $30 \mathrm{~m}$ from open water. Although the tidal fluctuation in the unconfined aquifer may be negligible compared with that in a confined aquifer, the unconfined aquifer may influence the tidal fluctuation in the underlying confined aquifer via leakage. Using mathematical procedures similar to those of Sun (1997), Jiao and Tang (1999) derived a one-dimensional analytical solution to investigate the influence of leakage on tidal response in a coastal leaky confined aquifer system. This solution was based on a conceptual model under the assumption that the groundwater head in the confined aquifer fluctuates in response to sea tide whereas that of the overlying unconfined aquifer remains constant. Their solution showed that the leakage has a significant impact on the tidal behaviour of the confined aquifer.

An attempt will be made in this study to derive a two-dimensional analytical solution of groundwater flow in response to tidal fluctuation in a leaky confined aquifer. The solution is an extension of the solutions of Sun (1997) and Jiao and Tang (1999). The solution will be compared with existing analytical solutions under simpler conditions. A numerical model will be developed to test the results from the analytical solution. On the basis of the analytical solution, the groundwater head distribution in a leaky confined aquifer in response to tidal boundaries is examined and the influence of leakage on groundwater fluctuation is discussed.

\section{CONCEPTUAL MODEL AND ANALYTICAL SOLUTION}

The configuration of the aquifer system is shown in Figure 1. The system has three layers: leaky confined aquifer, semi-permeable layer and unconfined aquifer. It is assumed that the shallow unconfined aquifer has a large specific yield, which can effectively damp the tidal effect so that the tidal fluctuation in the unconfined aquifer is negligible compared with that in the confined aquifer (Jiao and Tang, 1999). The groundwater head in the leaky confined aquifer will change with the tidal fluctuation in the open water on the left (sea or estuarine river). The origin of the system is selected to be at the left bottom of the front face of the leaky confined aquifer (Figure 1). The amplitude decreases and phase varies as the wave propagates into the $y$ direction. Owing of this boundary condition, the groundwater head in the leaky confined aquifer will change with $x$ and $y$. The aquifer material is homogeneous and isotropic. Assume that the flow velocity in the confined aquifer is essentially horizontal and there is vertical leakage through the semi-permeable layer. The initial groundwater head at time $=0$ in the whole system is uniform and equals $h_{z}$, which is the distance from the groundwater head to any convenient reference. When $t>0, h_{z}$ in the unconfined aquifer remains constant. Assume that the storage of the semi-permeable layer is negligible and that the leakage is linearly proportional to the difference in head between the two aquifers (Hantush and Jacob, 1955). Under these assumptions, the governing equation for the two-dimensional groundwater flow in the confined aquifer can be written as

$$
S \frac{\partial h}{\partial t}=T\left(\frac{\partial^{2} h}{\partial x^{2}}+\frac{\partial^{2} h}{\partial y^{2}}\right)+L\left(h_{z}-h\right)
$$

with a tidal boundary

$$
h(0, y, t)=h_{z}+A \mathrm{e}^{-m y} \cos (a t+b y+c)
$$

where $h(0, y, t)$ is the head at $x=0 ; S$ is the storability; $T$ is the transmissivity; $L$ is leakance or specific leakage (Hantush and Jacob, 1955; Hantush, 1960), which is the ratio of the hydraulic conductivity $\left(k^{\prime}\right)$ of the semiconfining unit over the thickness $\left(m^{\prime}\right)$ of the semiconfining unit; $A$ is the amplitude of the tidal change; $a$ is the tidal speed and equals $2 \pi / t_{o}$, where $t_{o}$ is the tidal period, or time for the tide to go from one extreme to the other (Fetter, 1994); $b$ is the separation coefficient, which defines the change of phase with distance; $m$ is the damping coefficient of tidal amplitude (Sun, 1997); and $c$ is the phase shift. 


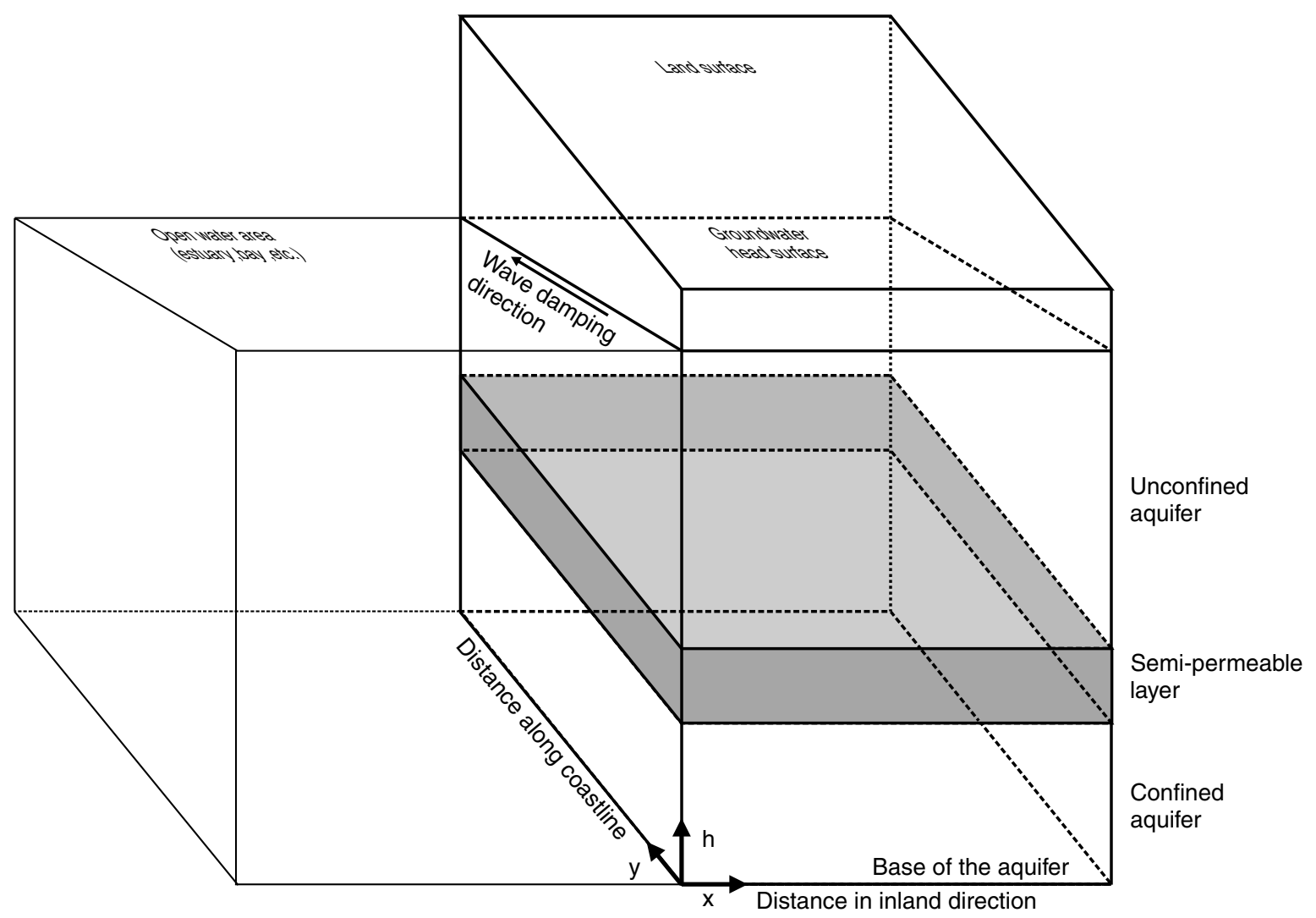

Figure 1. Conceptual model of two-dimensional groundwater flow in a leaky confined aquifer system near open tidal water

The boundary condition for Equation (1) on the inland side where $x$ approaches infinity is

$$
h(\infty, y, t)=h_{z}
$$

which states that the tide has no effect far inland as $x$ approaches infinity.

Equation (1) and boundary conditions (2) and (3) are very similar to those presented by Jiao and Tang (1999) and Sun (1997). They are different from Jiao and Tang in the sense that they are two-dimensional; they are different from Sun in the sense that they include leakage. The same analytical approach used by Sun (1997) or Jiao and Tang (1999) can be used to solve the above equations. Details are presented in the Appendix.

The solution to Equation (1) subject to boundary conditions (2) and (3) is (see Appendix)

$$
h(x, y, t)=h_{z}+A \mathrm{e}^{-p x-m y} \cos \left(a t+b y-\frac{a S+2 b m T}{2 p T} x+c\right)
$$

where $p$ is defined as

$$
p=\frac{1}{\sqrt{2}}\left\{\left[\left(b^{2}-m^{2}+\frac{L}{T}\right)^{2}+\left(\frac{a S}{T}+2 b m\right)^{2}\right]^{1 / 2}+b^{2}-m^{2}+\frac{L}{T}\right\}^{1 / 2}
$$


If the amplitude of tidal change at $y=0$ on the left boundary is $H_{0}$, the amplitude $(A)$ of tide along the left boundary is $H_{0} \mathrm{e}^{-m y}$, as can be seen from the boundary condition (2). On basis of Equation (4), the amplitude of groundwater head fluctuation in the confined aquifer is

$$
H(x, y)=H_{0} \mathrm{e}^{-p x-m y}
$$

\section{DISCUSSION OF THE ANALYTICAL SOLUTION}

\section{Summary of existing analytical solutions related to tidal fluctuations}

Some existing analytical solutions can be regarded as special cases of the solution presented in this paper. For example, Equation (4) has the same format as that of Sun (equation 16, 1997) except that $p$ is different. If there is no leakage ( $L=0 /$ day), the expression for $p$ becomes

$$
p=\frac{1}{\sqrt{2}}\left\{\left[\left(b^{2}-m^{2}\right)^{2}+\left(\frac{a S}{T}+2 b m\right)^{2}\right]^{1 / 2}+b^{2}-m^{2}\right\}^{1 / 2}
$$

which is identical to that of Sun (equation 14, 1997).

If the problem is one dimensional (without a $y$ component), the solution becomes

$$
h(x, t)=h_{z}+A \mathrm{e}^{-p x} \cos \left(a t-\frac{a S}{2 p T} x+c\right)
$$

with $p$ equal to

$$
p=\frac{1}{\sqrt{2}}\left\{\left[\left(\frac{L}{T}\right)^{2}+\left(\frac{a S}{T}\right)^{2}\right]^{1 / 2}+\frac{L}{T}\right\}^{1 / 2}
$$

The solution (8) is identical to the one-dimensional solution presented by Jiao and Tang (equation 4, 1999).

Table I summarizes some existing analytical solutions related to groundwater head in coastal aquifers. Note that, for the purposes of comparison, all the original equations by different authors are put into the same format using the same notations. For example, Jacob (1950) used sine oscillations, instead of cosine oscillations, in sea level and he did not consider a phase shift $(c=0)$.

\section{Solution for a boundary with multitidal constituents}

When Equation (4) is developed, it is assumed that at the tidal boundary there is only one tidal constituent, as shown by Equation (2). Usually, the boundary condition on the coastal side is a damped cosine function with different tidal constituents (Sun, 1997)

$$
h(0, y, t)=h_{z}+\sum_{k} A_{k} \mathrm{e}^{-m_{k} y} \cos \left(a_{k} t+b_{k} y+c_{k}\right)
$$

where $A_{k}, a_{k}, b_{k}, c_{k}$ and $m_{k}$ are the amplitude, the tidal speed, separation coefficient, phase shift and damping coefficient of the $k$ th tidal constituent. With such a boundary condition, the final solution $h(x, y, t)$ will be a linear superposition of $h(x, y, t)$ for different tidal constituents

$$
h(x, y, t)=h_{z}+\sum_{k} A_{k} \mathrm{e}^{-p_{k} x-m_{k} y} \cos \left(a_{k} t+b_{k} y-\frac{a_{k} S+2 b_{k} m_{k} T}{2 p_{k} T} x+c_{k}\right)
$$


Table I. Summary of some existing analytical solutions related to groundwater head in coastal aquifers

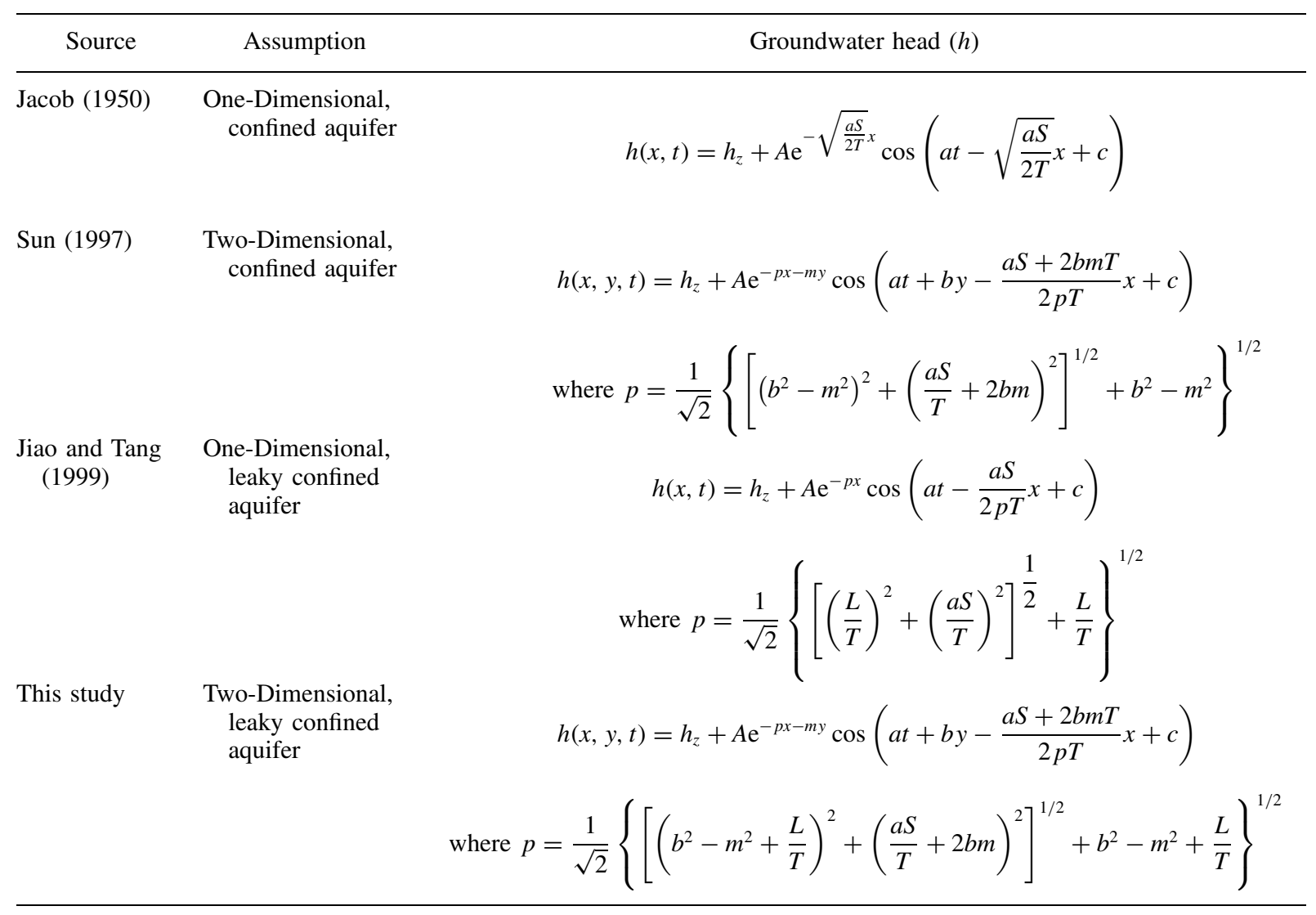

where

$$
p_{k}=\frac{1}{\sqrt{2}}\left\{\left[\left(b_{k}^{2}-m_{k}^{2}+\frac{L}{T}\right)^{2}+\left(\frac{a S}{T}+2 b_{k} m_{k}\right)^{2}\right]^{1 / 2}+b_{k}^{2}-m_{k}^{2}+\frac{L}{T}\right\}^{1 / 2}
$$

\section{Comparison of analytical solution and numerical simulation}

From Table I, it can be seen that the analytical solution derived in this study is identical to existing solutions for special cases such as one-dimensional flow and no leakage. To test the solution in more general cases, Equation (1) is also solved using an implicit finite-difference numerical model. The aquifer domain is assumed to be $3 \mathrm{~km} \times 50 \mathrm{~km}$. The domain is discretized into over 30000 cells of equal size, with $\Delta x=20 \mathrm{~m}$ and $\Delta y=200 \mathrm{~m}$. The time step is $1 \mathrm{~h}$. Above the confined aquifer, there is an aquifer that is unconfined with constant groundwater head. There is a leakage between the two aquifers, with specific leakage being $L=0 \cdot 001 / \mathrm{h}$. Other parameters are listed in Table II. These parameters were based on the tidal and hydraulic studies in Apalachicola Bay, Florida, USA (Sun, 1997) and are used directly for analytical and numerical studies in this paper. The boundary on the left is a tidal boundary condition and Equation (2) or (10) is used. The groundwater head at the boundary on the right is assumed to be unchanged during the simulation period so that the boundary condition (3) is used. No-flow boundary conditions are adopted at the boundaries with $y=0$ and $y=50 \mathrm{~km}$. The initial groundwater head is zero everywhere. The results of the numerical model, together with the results of the analytical solution under the same conditions, are presented in Table III. It 

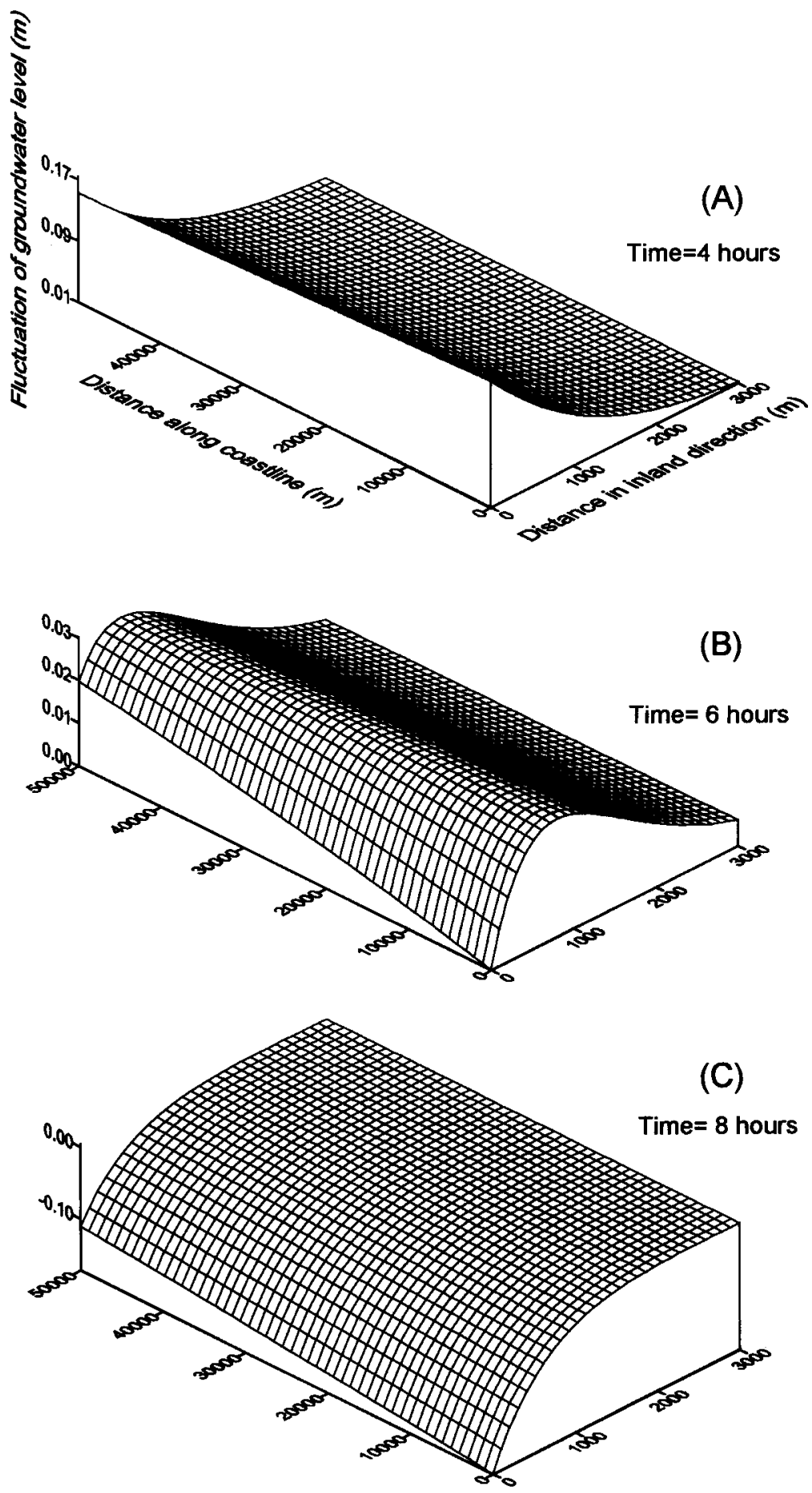

Figure 2. Groundwater head distributions in a leaky confined aquifer (specific leakage $=0 \cdot 001 / \mathrm{h}$ ) near open water with one diurnal tide when (A) time $=2 \mathrm{~h},(\mathrm{~B})$ time $=4 \mathrm{~h}$ and (C) time $=6 \mathrm{~h}$ 

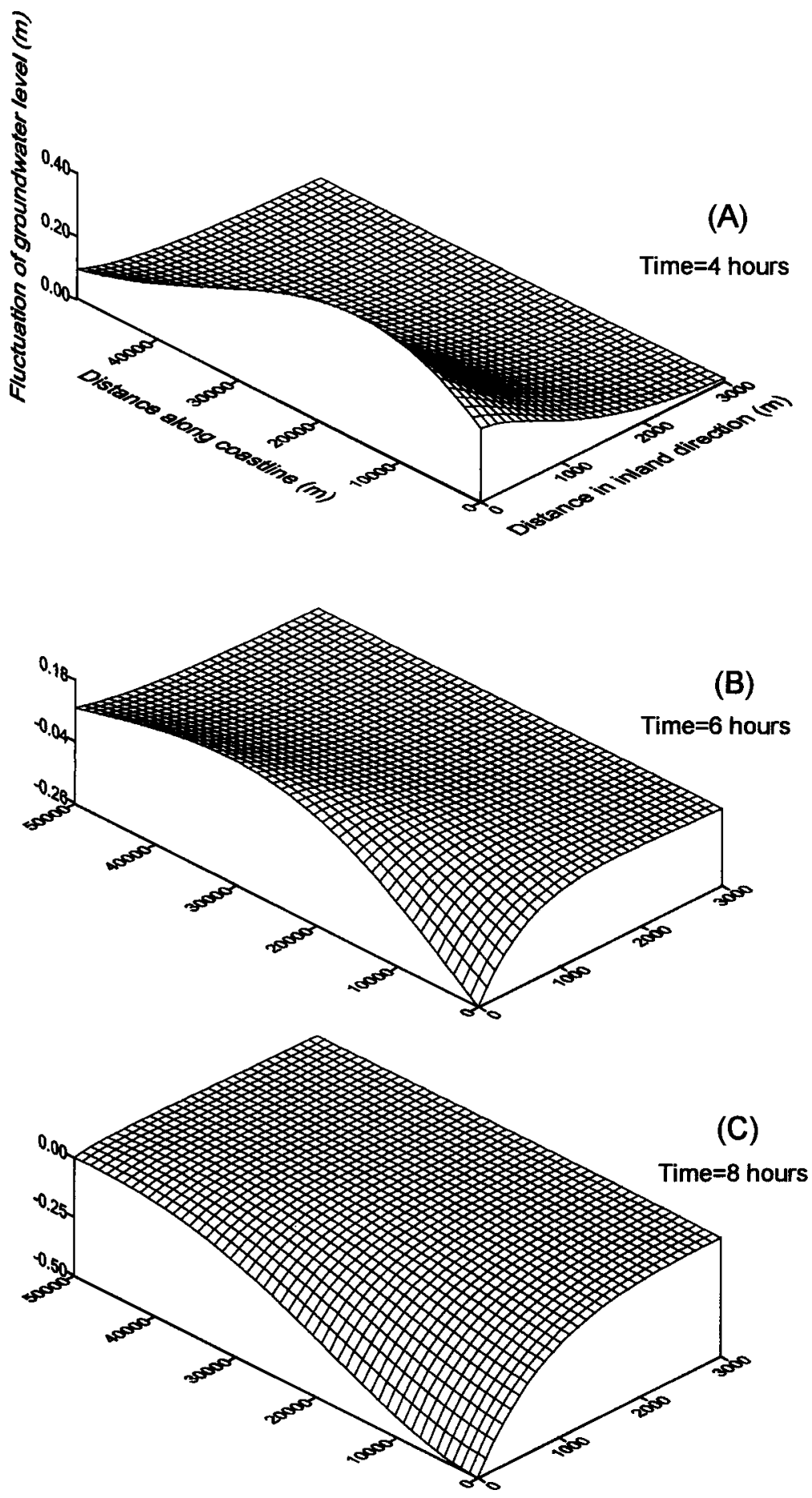

Figure 3. Groundwater head distributions in a leaky confined aquifer (specific leakage $=0 \cdot 001 / \mathrm{h}$ ) near open water with both diurnal and semidiurnal tides when $(\mathrm{A})$ time $=2 \mathrm{~h},(\mathrm{~B})$ time $=4 \mathrm{~h}$ and $(\mathrm{C})$ time $=6 \mathrm{~h}$ 
Figure $2 \mathrm{~B}$ shows how the wave propagates into the inland direction at time $=6 \mathrm{~h}$. At time $=8 \mathrm{~h}$, the groundwater head in a large part of the system becomes negative (Figure 2C). In the case of a boundary on the left with only one diurnal tidal component, the water level does not change much in the $y$ direction.

Figure 3 shows the groundwater head distribution in the case when the left-hand boundary condition is a linear superposition of diurnal and semidiurnal constituents. Compared with Figure 2, the pattern of groundwater head distribution is more complicated. The water level fluctuates considerably in both $x$ and $y$ directions. In general, the spatial and temporal distribution of groundwater head in a leaky confined aquifer has a similar pattern to that described by Sun (1997) for the case of no leakage.

To understand the influence of leakage on the fluctuation of groundwater head, the analytical equation is analysed using different specific leakage. Figure 4 shows how the groundwater head changes with specific leakage at time $=18 \mathrm{~h}$ when the boundary on the left has only a diurnal tide. Take the profile at $y=0$ for example. In the case of no leakage, the groundwater head fluctuates greatly (Figure 4A). The maximum fluctuation is $0.10 \mathrm{~m}$ and is located at $x=1.1 \mathrm{~km}$. When $L$ is increased to $0.005 / \mathrm{h}$ (Figure $4 \mathrm{~B}$ ), the maximum fluctuation at the same profile is less than about $0.01 \mathrm{~m}$ and is located at $x=0.4 \mathrm{~km}$. Fluctuation becomes zero when $x$ is greater than $1.5 \mathrm{~km}$. When $L$ is increased to $0.01 / \mathrm{h}$ (Figure $4 \mathrm{C}$ ), the fluctuation at this profile is even smaller. The maximum fluctuation is only $0.004 \mathrm{~m}$ and is at $x=0.3 \mathrm{~km}$ and the fluctuation is zero when $x>0.9 \mathrm{~km}$. It can be seen that both tidal amplitude of groundwater head in the aquifer and the distance over which the aquifer can be disturbed by the sea tide will be considerably reduced owing to the existence of leakage. This feature is the same as that of one-dimensional tidal groundwater flow in leaky confined aquifers described by Jiao and Tang (1999).

\section{Discussion of the influence of storage of the quitard on the solution}

An important assumption in the study is that the storage of the semipermeable formation is negligible. To understand the possible error caused by this assumption, the numerical model is modified to include the storage. The output of the numerical model is compared with that of the previous numerical model, which ignores the storage, and the error (difference between the outputs) is calculated. Table IV shows how the error statistic results, such as the maximum error and mean error, change with the specific storage of the semipermeable layer. Other parameters are the same as shown in Table II. It can be seen that the error is generally very small. The error increases with specific storage. It is possible that the assumption which ignores the specific storage is not valid when $S_{\mathrm{s}}$ is larger than a certain value. Detailed discussion on the impact of the specific storage on the groundwater level fluctuation in the main aquifer can be found in Li and Jiao (in press).

\section{SUMMARY}

This paper presents a two-dimensional analytical solution for groundwater head distribution in a leaky confined aquifer near open water with single or multiple tidal fluctuation components. For one-dimensional flow in a leaky confined aquifer or two-dimensional flow in a non-leaky confined aquifer, the solution becomes identical to the solutions derived by Jiao and Tang (1999) and Sun (1997). The analytical solution is further tested against the results of the numerical simulation. The discussion about the spatial distribution of groundwater head near the coast shows that the groundwater surface can be very complicated if the tidal boundary has several tidal constituents. Groundwater response in coastal area depends not only on the aquifer properties and structures but also the wave pattern. The hypothetical studies indicate that the tidal fluctuation in the confined aquifer can be damped significantly if there is leakage between the unconfined and confined aquifers. 

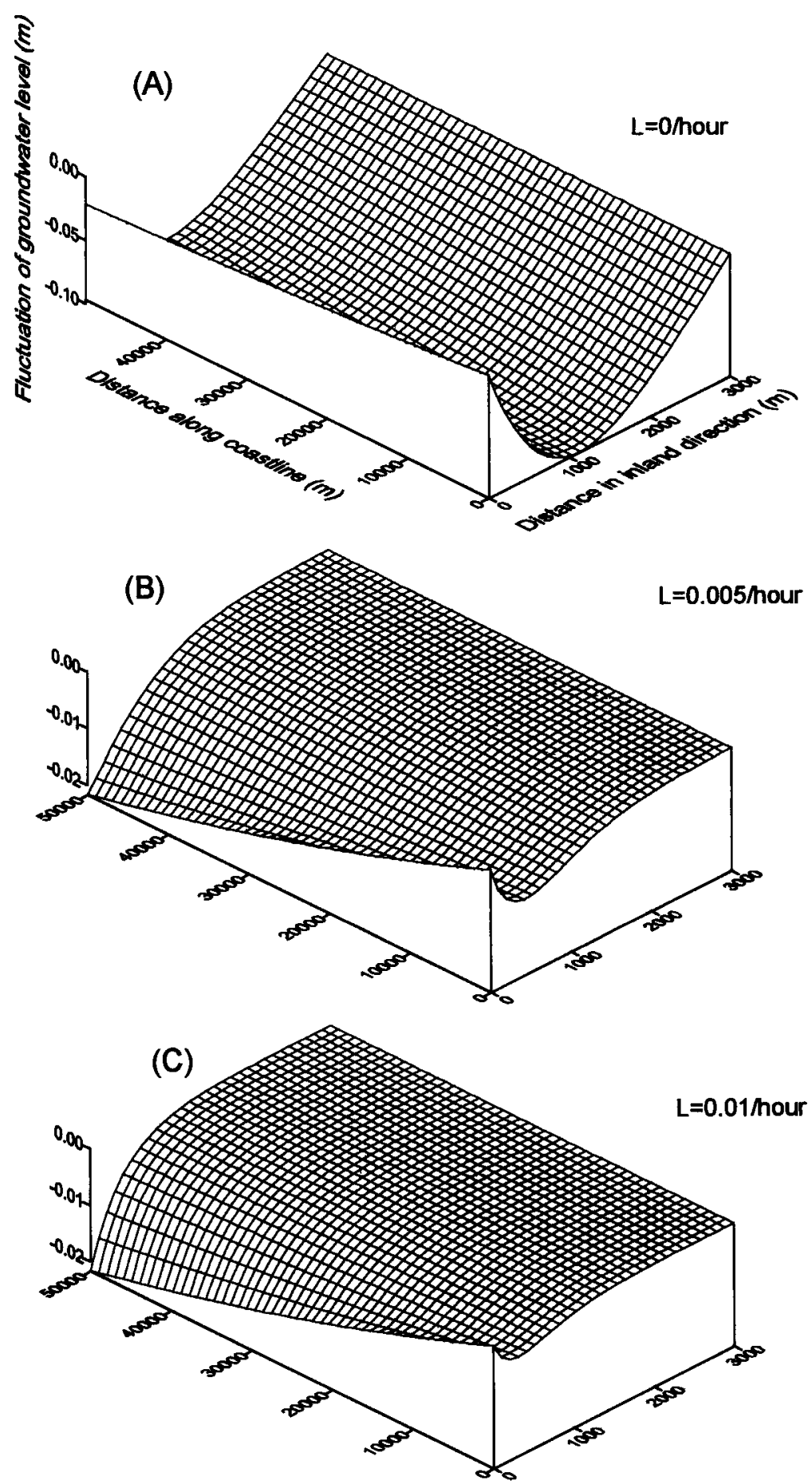

Figure 4. Groundwater head distributions in a leaky confined aquifer near open water with one diurnal tide when specific leakage $=(\mathrm{A}) 0 / \mathrm{h}$, (B) $0 \cdot 005 / \mathrm{h}$ and (C) $0 \cdot 01 / \mathrm{h}$ at time $=18 \mathrm{~h}$ 
Table IV. Error statistics for different values of specific storage of the semipermeable layer when $m^{\prime}=10 \mathrm{~m}$ and $k^{\prime}=0 \cdot 01 \mathrm{~m} / \mathrm{h}$

\begin{tabular}{|c|c|c|c|c|c|}
\hline $\begin{array}{c}\text { Specific } \\
\text { Storage }\left(S_{\mathrm{s}}\right) \\
\left(\mathrm{m}^{-1}\right)\end{array}$ & $\begin{array}{l}\text { Time } \\
\text { (h) }\end{array}$ & $\begin{array}{l}\text { Max } \\
\text { head }\end{array}$ & $\begin{array}{l}\text { Max } \\
\text { Error }\end{array}$ & $\begin{array}{l}\text { Mean } \\
\text { Error }\end{array}$ & Variance \\
\hline $0 \cdot 001$ & $\begin{array}{l}4 \\
6 \\
8\end{array}$ & $\begin{array}{l}0 \cdot 1710 \\
0 \cdot 0304 \\
0 \cdot 1710\end{array}$ & $\begin{array}{l}0.0064 \\
0.0035 \\
0.0090\end{array}$ & $\begin{array}{l}0.0033 \\
0 \cdot 0011 \\
0 \cdot 0033\end{array}$ & $\begin{array}{l}0.0020 \\
0 \cdot 0018 \\
0 \cdot 0071\end{array}$ \\
\hline $0 \cdot 0001$ & $\begin{array}{l}4 \\
6 \\
8\end{array}$ & $\begin{array}{l}0 \cdot 1710 \\
0 \cdot 0304 \\
0 \cdot 1710\end{array}$ & $\begin{array}{l}0 \cdot 0040 \\
0 \cdot 0017 \\
0 \cdot 0020\end{array}$ & $\begin{array}{l}0 \cdot 0020 \\
0 \cdot 0010 \\
0 \cdot 0006\end{array}$ & $\begin{array}{l}0.0012 \\
0.0006 \\
0.0012\end{array}$ \\
\hline $0 \cdot 00001$ & $\begin{array}{l}4 \\
6 \\
8\end{array}$ & $\begin{array}{l}0 \cdot 1710 \\
0 \cdot 0304 \\
0 \cdot 1710\end{array}$ & $\begin{array}{l}0.0040 \\
0 \cdot 0022 \\
0 \cdot 0012\end{array}$ & $\begin{array}{l}0 \cdot 0020 \\
0 \cdot 0013 \\
0 \cdot 0004\end{array}$ & $\begin{array}{l}0.0012 \\
0 \cdot 0007 \\
0.0006\end{array}$ \\
\hline $0 \cdot 000001$ & $\begin{array}{l}4 \\
6 \\
8\end{array}$ & $\begin{array}{l}0 \cdot 1710 \\
0.0304 \\
0 \cdot 1710\end{array}$ & $\begin{array}{l}0.0040 \\
0 \cdot 0023 \\
0 \cdot 0012\end{array}$ & $\begin{array}{c}0 \cdot 0020 \\
0 \cdot 0013 \\
0 \cdot 0003\end{array}$ & $\begin{array}{l}0.0012 \\
0 \cdot 0007 \\
0.0006\end{array}$ \\
\hline
\end{tabular}

\section{ACKNOWLEDGEMENT}

This research is supported by the Dr Stephen S. F. Hui Trust Fund at the University of Hong Kong.

\section{APPENDIX}

The mathematical procedures to solve Equation (1) subject to boundary conditions (2) and (3) are almost the same as those of Jiao and Tang (1999). The only difference is that the equation here is two-dimensional. For convenience of reference, the procedures are presented here, as follows.

Let $H=h-h_{z}$, and Equations (1)-(3) become

$$
\begin{aligned}
S \frac{\partial h}{\partial t} & =T\left(\frac{\partial^{2} h}{\partial x^{2}}+\frac{\partial^{2} h}{\partial y^{2}}\right)-L H \\
h(0, y, t) & =A \mathrm{e}^{-m y} \cos (a t+b y+c) \\
h(\infty, y, t) & =0
\end{aligned}
$$

From Equation (A2)

$$
H(0, y, t)=A \operatorname{Re}\left[\mathrm{e}^{-m y} \mathrm{e}^{i(a t+b y+c)}\right]
$$

where Re denotes the real part of the complex equation $\mathrm{e}^{-m y} \mathrm{e}^{i(a t+b y+c)}$ and $i^{2}=-1$.

Given the form of boundary condition (A2), the solution for (A1) must be in the form

$$
H(x, y, t)=A \mathrm{e}^{\lambda x} \mathrm{e}^{-m y} \mathrm{e}^{i(a t+b y+c)}
$$

Substituting Equation (A5) into (A1) gives

$$
\lambda^{2}=b^{2}-m^{2}+\frac{L}{T}+i\left(\frac{a S}{T}+2 b m\right)
$$

where $\lambda$ must be a complex number. 
Let $\lambda=-p+i q$ for $p>0$. Substituting $\lambda=-p+i q$ into Equation (A6), and equating the real and imaginary parts of both sides of the equation, respectively, give

$$
\begin{aligned}
p^{2}-q^{2} & =b^{2}-m^{2}+\frac{L}{T} \\
-2 p q & =\frac{a S}{T}+2 b m
\end{aligned}
$$

In order to solve for $p$ and $q$, add the square of Equations (A7) and (A8)

$$
p^{2}+q^{2}=\left[\left(b^{2}-m^{2}+\frac{L}{T}\right)^{2}+\left(\frac{a S}{T}+2 b m\right)^{2}\right]^{1 / 2}
$$

Then add Equation (A7) and (A9), where it follows directly from Equation (A8) that

$$
\begin{aligned}
& p=\frac{1}{\sqrt{2}}\left\{\left[\left(b^{2}-m^{2}+\frac{L}{T}\right)^{2}+\left(\frac{a S}{T}+2 b m\right)^{2}\right]^{1 / 2}+b^{2}-m^{2}+\frac{L}{T}\right\}^{1 / 2} \\
& q=-\frac{a S+2 b m T}{2 p T}
\end{aligned}
$$

Substituting ( $\lambda=-p+i q$ ) into Equation (A5), and using the tidal boundary condition (A2) lead to

$$
\begin{aligned}
H(x, y, t) & =A \operatorname{Re}\left\{\exp \left[-p x-m y+i\left(a t+b y-\frac{a S+2 b m T}{2 p T} x+c\right)\right]\right\} \\
& =A \mathrm{e}^{-p x-m y} \cos \left(a t+b y-\frac{a S+2 b m T}{2 p T} x+c\right)
\end{aligned}
$$

Finally, the solution to Equation (1) subject to the boundary conditions (2) and (3)

$$
h(x, y, t)=h_{z}+A e^{-p x-m y} \cos \left(a t+b y-\frac{a S+2 b m T}{2 p T} x+c\right)
$$

where $p$ is defined as in Equation (A10).

\section{REFERENCES}

Chen CX, Jiao JJ. 1999. Numerical simulation of pumping tests in multilayer wells with non-darcian flow in the wellbore. Ground Water 37(3): 465-474.

Erskine AD. 1991. The effect of tidal fluctuation on a coastal aquifer in the U. K. Ground Water 29(4): 556-562.

Ferris JG. 1951. Cyclic fluctuations of water level as a basis for determining aquifer transmissibility. International Association of Hydrological Sciences Publication 33: 148-155.

Fetter CW, 1994. Applied Hydrogeology. Prentice-Hall; 376 pp.

Hantush MS, 1960. Modification of the theory of leaky aquifers. Journal of Geophysical Research 65(11): $3713-3716$.

Hantush MS, Jacob CE. 1955. Nonsteady radial flow in an infinite leaky aquifer. EOS (Transactions American Geophysical Union) 36(1): $95-100$.

Hong Kong Observatory. 1999. Tide Tables for Hong Kong.

Jacob CE, 1950. Flow of ground-water. In Engineering Hydraulics, Rouse H. (ed.). Wiley: New York; $321-386$.

Jiao JJ, Tang Z. 1999. An analytical solution of groundwater response to tidal fluctuation in a leaky confined aquifer. Water Resources Research 35(3): 747-751.

Li H, Jiao JJ. In press. Analytical studies of groundwater-level fluctuation in a coastal confined aquifer overlain by a semi-permeable layer with storage. Advances is Water Resources 24(5): 565-573.

Liu KF. 1996. Tide-induced ground-water flow in deep confined aquifer. Journal of Hydraulic Engineering 122(2): $104-110$.

Millham NP, Howes BL. 1995. A comparison of methods to determine K in a shallow coastal aquifer. Ground Water 33(1): 49-57. 
Money MS. 1986. Tidal variations of groundwater head in an estuarine aquifer. In Groundwater in Engineering Geology, Cripps JC, Bell FG, Culshaw MG (eds). Engineering Geology Special Publication No. 3, Geological Society of London: London; 81-85.

Pontin JMA. 1986. Prediction of groundwater pressures and uplift below excavations in tidal limits. In Groundwater in Engineering Geology, Cripps JC et al. (eds). Engineering Geology Special Publication No. 3, Geological Society of London: London; $333-366$.

Sun H. 1997. A two-dimensional analytical solution of groundwater response to tidal loading in an estuary. Water Resources Research 33(6): 1429-1435.

White JK, Roberts TOL. 1994. The significance of groundwater tidal fluctuations. Proceedings of the International Conference Organized by the Institution of Civil Engineers, London, Wilkinson WB (ed.); 31-42. 